\title{
EM BUSCA DO PARTIDARISMO: UM ESTUDO DE CASO SOBRE O HGPE PARA DEPUTADO FEDERAL NAS ELEIÇÕES DE $2010^{1}$
}

\author{
Geison da Cunba Ferreira ${ }^{2}$
}

\begin{abstract}
Resumo
O objetivo central do artigo é analisar o papel dos partidos políticos no Horário Gratuito de Propaganda Eleitoral (HGPE) para a Câmara dos Deputados (CD), no estado do Rio Grande do Sul, quinto maior colégio eleitoral do Brasil, na eleição de 2010. O diagnóstico baseia-se na construção da imagem partidária durante a campanha eleitoral pela televisão e na distribuição do tempo de TV pelos partidos entre os candidatos. O método utilizado na pesquisa foi o quantitativo, com base na propaganda eleitoral de 11 (onze) partidos, todos com representação na CD durante a legislatura de 2007 a 2011. Os resultados finais indicam a forte presença de referências partidárias nas campanhas de PT e PTB e a distribuição homogênea do tempo de televisão na maioria dos partidos, com exceção de partidos menores como PSB, PCdoB e PSOL.
\end{abstract}

Palavras-chave: campanha eleitoral; partidos políticos; eleições proporcionais.

\begin{abstract}
The main objective of this paper is to analyze the role of political parties in the free TV campaign advertising, called HGPE in Brazil, to the Brazilian House of Representatives (CD), in the state of Rio Grande do Sul, the fifth largest electoral college of the elections in Brazil, in the 2010 elections. The diagnosis is based on the construction of party image during the free TV campaign advertising and the distribution of TV time by the parties among candidates. The methodology utilized in this research was quantitative, based on the electoral advertising of 11 parties, all represented in the CD during the legislature from 2007 to 2011. The final results indicate the strong presence of partisan references in the PT and PTB campaigns and the homogeneous distribution of TV time in most parties, with the exception of smaller parties as PSB, PCdoB and PSOL.
\end{abstract}

Keywords: election campaign; political parties; proportional elections.

\section{Resumen}

El objetivo central del trabajo es analizar el papel de los partidos políticos en la propaganda electoral gratuita en la televisión (el HGPE en Brasil) para la Cámara de Diputados (CD), en el estado de Rio Grande do Sul, el quinto mayor colegio electoral de Brasil, en las elecciones de 2010. El diagnóstico se basa en la construcción de la imagen de los partidos en la propaganda electoral y en la distribución del tiempo de exposición en la televisión por los partidos entre los candidatos. La metodología de investigación fue cuantitativa, con base en la publicidad televisiva de 11 (once) partidos, todos ellos representados en la CD entre los años 2007-2011. Los resultados finales indican la fuerte presencia de las referencias partidarias en las campañas del PT y PTB y la distribución homogénea del tiempo de televisión en la mayoría de los partidos, con la excepción de los partidos más pequeños como PSB, PCdoB y PSOL.

Palabras clave: campaña electoral; los partidos políticos; elecciones proporcionales.

\section{INTRODUÇÃO}

O presente estudo trata do papel e da relevância dos partidos políticos brasileiros na propaganda eleitoral em eleições proporcionais. O modelo da campanha televisiva vigente no país é, aqui, encarado como possibilidade de reforço do "partidarismo" eleitoral e da imagem pública das siglas frente ao chamado "individualismo político", de longa tradição na

\footnotetext{
${ }^{1}$ DOI deste artigo: $10.5380 /$ recp.v6i1.39023.

2 Bacharel e Licenciado em Ciências Sociais pela UFRGS. Mestre em Ciências Sociais pela PUCRS.
} 
política brasileira. Sobre o papel cumprido pelo HGPE e pelos partidos políticos nas eleições proporcionais brasileiras, cabe lembrar, já de início, um dos desdobramentos do raciocínio de Mainwaring (1991) em seu conhecido estudo sobre o sistema proporcional de "lista aberta"” ainda vigente no país: a dificuldade - ou impossibilidade - de os partidos fixarem uma marca pública ou terem algum peso na competição eleitoral. Devido, dentre outros fatores, à adoção do voto preferencial ${ }^{4}$ e ao alto número de candidatos haveria, segundo o autor, um poderoso incentivo ao individualismo político no Brasil, autorizando, para se utilizar uma expressão forte do mesmo, um verdadeiro "jogo livre"5 (MAINWARING, 1991, P. 47) na disputa pelos cargos legislativos. No entanto, o próprio brasilianista aponta importante exceção à "regra" do incentivo ao individualismo dentro da legislação eleitoral ao lembrar que o tempo do horário eleitoral na televisão e no rádio é, por ela, reservado e distribuído aos partidos políticos (MAINWARING, 1991, P. 43). Essa "exceção à regra" é o que interessa diretamente à análise aqui proposta.

A utilização partidária do HGPE é possível em virtude, em primeiro lugar, da configuração atual da legislação eleitoral brasileira. Existe no Brasil um incentivo legal para que os partidos, por monopolizarem o tempo de televisão, recorram à promoção de sua imagem pública, reforçando o "partidarismo" enquanto estratégia para angariar votos. Nesse aspecto específico, a legislação caracterizada como "promíscua” por Mainwaring (1991) acaba por incentivar certa regulação partidária das campanhas proporcionais que as distancia do "jogo livre" defendido pelo brasilianista. Afinal, formalmente "o modelo de propaganda política na televisão vigente obriga a que os interesses individuais dos candidatos se subordinem às estratégias coletivas dos partidos, uma vez que o tempo na televisão é destinado a estes" (DIAS, 2009, P. 3).

Em segundo lugar, tratando da organização e da gramática específica do HGPE nas eleições proporcionais, se deve afirmar que a escassez de tempo para exposição dos candidatos individualmente pode estimular justamente a opção por estratégias de caráter partidário de atração de voto e de promoção das legendas naquele espaço com o objetivo de se "simplificar" a "mensagem" emitida ao eleitor. O apelo ao "voto de legenda" pode ser uma dessas opções, mas não necessariamente a única (DIAS, 2009; 2011). Por fim, Dias (2009; 2013) lembra que há uma característica de incentivo ao partidarismo no HGPE presente no âmago do sistemCERTAa eleitoral brasileiro: “o método eleitoral para a eleição

\footnotetext{
${ }^{3} \mathrm{Ou}$, tecnicamente, "lista preferencial não ordenada".

4 O autor utiliza a expressão "voto uninominal" para definir a estrutura de votação em sistemas de lista aberta. No presente trabalho, adotou-se, seguindo a recomendação de Nicolau (2006), a expressão "voto preferencial".

5 Para um balanço mais detalhado das críticas de Mainwaring (1991) ao sistema proporcional de "lista aberta" e à legislação eleitoral brasileira, ver Ferreira (2012).
} 
de cargos legislativos é o da proporcionalidade” (DIAS, 2009, P.16). Pelo fato de o número de cadeiras obtido pelo partido ser "determinado pela soma total de seus votos, seja os que foram dados aos candidatos individualmente, seja à legenda do partido" (DIAS, 2013, P.203), determinadas estratégias teriam, por isso, a finalidade específica de reforçar o cociente eleitoral por meio do "voto partidário", fortalecendo a imagem pública das siglas.

A partir dessa discussão teórica referente ao impacto do HGPE sobre o “individualismo político" presente nas eleições proporcionais brasileiras, será analisado um conjunto de peças ${ }^{6}$ do Horário Gratuito de Propaganda Eleitoral (HGPE) para o cargo de Deputado Federal no estado do Rio Grande do Sul, quinto maior colégio eleitoral do Brasil, nas eleições de 2010. A primeira parte do artigo faz um rápido apanhado sobre o HGPE, enfatizando, em linhas gerais, o debate sobre sua eficácia eleitoral e sobre os efeitos do monopólio do tempo de televisão e rádio pelos partidos políticos nas campanhas eleitorais brasileiras. Na segunda parte, faz-se uma rápida apresentação do contexto eleitoral de 2010 e passa-se, então, à análise da utilização partidária do tempo na propaganda eleitoral objeto deste estudo. Interessa menos, nesse ponto, atribuir uma "relação causal entre o HGPE e maior número de votos" (CERVI, 2011, P.108). A tarefa principal, no caso, é investigar a distribuição do "bem escasso" (CERVI, 2011) tempo de exposição televisiva enquanto uma espécie de "incentivo seletivo" (PANEBIANCO, 2005) aos candidatos e, além disso, avaliar se, na efetivação dessa prática, há alguma interferência do tempo de vinculação entre candidatos e seus partidos.

Na parte final do texto, trata-se da "visibilidade partidária" e da "qualidade dessa visibilidade" (DIAS, 2013, P. 200) no HGPE em análise. Traça-se, assim, um panorama geral e comparativo da construção da imagem partidária, buscando verificar a variação da presença de diferentes tipos de estratégias eleitorais e a discussão das possíveis razões para esse fenômeno.

Para a empreitada analítica proposta, parte-se de duas hipóteses básicas, quais sejam: a) A disposição dos partidos ao longo do eixo esquerda/direita tem influência sobre a incidência, maior ou menor, de "simbologia partidária" na utilização do espaço de cada sigla na propaganda eleitoral gratuita proporcional; b) A distribuição interna aos candidatos, em cada partido, do tempo de exposição individual na propaganda televisiva tende a valorizar o grau de vinculação entre cada postulante e sua sigla.

\footnotetext{
"Cada "peça" ou "segmento" dos programas eleitorais estudados teve análise em separado. Conforme Dias (2013), "um segmento, ou peça, corresponde a cada cena do programa que organiza uma mensagem, que é transmitida por um ou mais personagens” (DIAS,2013, P.219).
} 


\section{BREVES CONSIDERAÇÕES SOBRE HORÁRIO GRATUITO DE PROPAGANDA}

\section{ELEITORAL BRASILEIRO}

O HGPE brasileiro pode servir aos mais diversos objetivos: apresentação dos candidatos, das propostas, para divulgação de atos de campanha, conforme descrito já no estudo pioneiro de Albuquerque (1999) sobre o tema. Em termos de audiência e de apelo público, seu desempenho é relevante: basta lembrar as intensas movimentações das direções partidárias, antes de cada disputa eleitoral, para ampliação das coligações eleitorais com o objetivo, em parte, de aumentar a fatia de cada candidatura no tempo de televisão (ANDRADE DOS SANTOS, 2011, P.32; CERVI, 2011, P.110). Dados recentes demonstram que a campanha eletrônica pela televisão é, sim, uma ferramenta privilegiada de acesso ao eleitor, sendo que seus “(...) índices seriam similares aos maiores sucessos da programação televisiva no Brasil" 7 (DIAS, 2011, P. 2). Para Schmitt et al. (1999), o horário eleitoral gratuito é, assim, “(...) com toda certeza uma das duas ou três fontes de informação políticas mais importantes para a população" (SCHMITT et al.,1999, P.293).

Por essas razões, o HGPE tem sido alvo de investigação constante pela ciência política brasileira como pano de fundo para a abordagem empírica de um fenômeno de grande relevância social e política em tempos atuais (no Brasil e no mundo): a interface cada vez maior entre os meios de comunicação (especificamente, a televisão) e o processo político - organizações partidárias, em especial ${ }^{8}$. Trabalhos específicos de Dias (2009) e Schmitt et al. (1999) têm, nesse ponto, buscado investigar o uso específico do HGPE brasileiro nas eleições proporcionais, avaliando sua formatação e gramática peculiar, assim como as conexões entre o sistema eleitoral brasileiro e as estratégias eleitorais empregadas naquele espaço. Esses autores sustentam, basicamente, que a proliferação de "identificadores partidários" no HGPE nas proporcionais pode atuar no sentido do reforço da imagem pública dos partidos, questionando, como defende Samuels (1997), a interpretação presente na "sabedoria convencional" sobre sistema partidário brasileiro acerca da impossibilidade de cultivo de estratégias que busquem o fomento da reputação partidária junto ao eleitor.

O fato de a legislação eleitoral brasileira, especificamente a Lei no $9.504 / 97$, vedar a propaganda paga e ceder o tempo na mídia aos partidos “os torna intermediários indispensáveis das campanhas através do rádio e da televisão" (ALBUQUERQUE, 2005, P. 30). Ames (2003), que qualifica as normas que regulam a campanha eleitoral brasileira como

\footnotetext{
${ }^{7}$ Conforme a autora, "os dados do Datafolha confirmam a alta audiência do HGPE: no primeiro turno de 2010, em média, 53\% dos entrevistados afirmaram terem assistido, mesmo que eventualmente, à campanha na televisão, enquanto no segundo turno essa média subiu para 60\%” (DIAS, 2011, P. 2).

8 Para uma discussão teórica aprofundada sobre esse tema, enfocando o modelo de propaganda eleitoral brasileiro e campo de pesquisa da chamada "Comunicação Política", ver Dias e Albuquerque (2002).
} 
"permissivas" e "restritivas", define o modelo do HGPE como exemplo de "norma restritiva" exatamente pelo fato de o tempo ser distribuído aos partidos e "pelos partidos de acordo com a importância da disputa de que participa o candidato, de modo que centenas deles somente são contemplados com alguns segundos por semana" (AMES, 2003, P.64). Cervi (2011) alerta para a utilização do HGPE brasileiro como recurso estratégico pelas direções partidárias nas eleições proporcionais, sendo o tempo de TV um "bem escasso" a ser distribuído conforme as escolhas internas aos partidos. Tal possibilidade é reforçada, ainda, pelo fato de a propaganda nas proporcionais ser orçada em muitos partidos de forma "casada" com a campanha majoritária, sem qualquer ônus financeiro direto para os candidatos ${ }^{9}$.

Schmitt et al. (1999), em estudo pioneiro, sustentou que o horário eleitoral constituise em uma espécie de lista ou ordenamento informal dos candidatos. Para os autores, a correlação entre votação e tempo de TV, de candidatos e partidos, no HGPE, sugere "a configuração de um sistema" em que os partidos atuam como "agentes efetivos" na definição dos resultados eleitorais (SCHMITT et al., 1999, P. 298). No entanto, a eficácia eleitoral da campanha televisiva nas proporcionais tem sido, nos últimos anos, questionada empiricamente pela literatura especializada (ALBUQUERQUE et al., 2008; ALBUQUERQUE, 2009).

De forma mais cautelosa, o que se pode afirmar é que a exposição diferenciada de candidatos no HGPE se caracteriza, no mínimo, como um indício de hierarquização da lista e de influência das direções partidárias naquele espaço, independentemente das razões que possam justificar essa prática ou de como cada partido lida internamente com suas "zonas de incerteza" (PANEBIANCO, 2005; MIGUEL, 2010). Como o HGPE é um espaço partidário por excelência, se o candidato ali tem um maior destaque, alguma "importância" ele possui para o partido (ALBUQUERQUE, 2009). A partir disso, ao se considerar que "do mesmo modo que há o conceito de partidos relevantes (isto é, os que realmente contam) na arena legislativa, há candidatos efetivos, relevantes na arena eleitoral" (KLEIN, 2007, P. 66), torna-se possível vislumbrar, pelo HGPE, de forma "relativamente simplificada", como cada partido lida com a competição eleitoral (SCHMITTT et al., 1999, P. 297).

Albuquerque (2009), utilizando o conceito de "incentivos seletivos" proposto por Panebianco (2005), lançou, por exemplo, uma hipótese nova de que, para além da projeção de desempenho de cada candidato, "a distribuição do tempo no HGPE teria como principal

\footnotetext{
9 Essa prática foi confidenciada ao autor em entrevistas com dirigentes partidários para a dissertação de mestrado que deu origem ao presente trabalho.
} 
propósito atender às demandas de poder internas ao partido" (ALBUQUERQUE, 2009, P. 6-7). Em perspectiva contrária, Carneiro (2009), em extenso estudo sobre a composição de listas partidárias nas eleições para deputado federal no Rio de Janeiro, afirma que é a partir da projeção mesmo do desempenho individual dos candidatos que "as listas são confeccionadas com uma espécie de ordenamento interno desconhecido dos eleitores" (CARNEIRO, 2009, P. 140). Conforme dirigentes entrevistados pela autora, os partidos focariam as campanhas em candidatos prioritários (chamados de "puxadores de legenda" ou "cabeça de chapa"). E os demais candidatos ("rabo da chapa") teriam um papel de complementar na nominata, somando votos (CARNEIRO, 2009, P.140-141).

Porém, considerando os diversos fatores intervenientes nos processos eleitorais, não se deve, de fato, sobredimensionar o peso eleitoral da presença dos candidatos ao legislativo na televisão como se tempo de TV e voto tivessem uma relação autoexplicativa. A despeito da evolução do papel da mídia eletrônica na política contemporânea, as disputas eleitorais são permeadas por diversos fatores como financiamento de campanha, arregimentação e acionamento de redes de militância, cociente eleitoral, tamanho do partido, coligação, etc. A pulverização do tempo entre os candidatos também torna, além disso, o HGPE menos efetivo na proporcional, de forma que, nela, os candidatos "ainda dependem pesadamente de formas "pré-televisivas" de campanha (porta a porta, reuniões em clubes e associações, "santinhos")" (MIGUEL, 2010, P.154). Por outro lado, se compreendermos a eficácia do HGPE nas proporcionais desde uma perspectiva minimalista, é fato que esse mecanismo pode proporcionar não apenas uma melhor publicização das candidaturas (em comparação com outros meios), mas também o reforço da intenção de votar e das informações e contatos prévios que o eleitor já tenha tido com o conjunto de propostas do candidato (por outras vias, diretas ou indiretas). Assim, o horário eleitoral pode cumprir, em potencial, três funções nas campanhas proporcionais: avisar os eleitores que alguém está se candidatando, relembrar uma candidatura para quem já foi "atingido" por outros meios de difusão de informação política e, em seu tempo exíguo, reforçar os "pontos centrais" do discurso de campanha dos candidatos (MIGUEL, 2010, P.154).

Conforme Popkin (1994), as campanhas eleitorais enviam uma espécie de mensagem, disponibilizando informações que, uma vez absorvidas pelo eleitor, são checadas por outras vias como, por exemplo, as relações interpessoais. Isto é, o eleitor faz a "checagem", mesmo que de forma primária e pouco sofisticada, das informações que recebe da campanha e, somente a partir daí, elas podem fazer algum efeito (POPKIN, 1994, P.48). Partindo desse raciocínio, se deve encarar o HGPE como tendo uma capacidade de influenciar no processo 
eleitoral que, por assim dizer, sempre estará conectada com as outras estratégias (mais tradicionais e presenciais) de campanha de cada candidato: comícios, visitas, caminhadas, distribuição de material impresso, mala direta, etc.

Dito isso, o que se quer é atentar, neste trabalho, para a relevância do estudo acadêmico do HGPE nas proporcionais, em primeiro lugar, por uma questão fática: em sendo eficaz ou não, boa parte do tempo destinado à campanha eleitoral "eletrônica", de rádio e de televisão, de dois em dois anos, em cada eleição, é ocupada por ele (MIGUEL, 2010, P. 152-153). E, em segundo lugar, como dito na introdução deste estudo, pelo papel cumprido pelo HGPE, no Brasil, enquanto possível reforço, dentro do contexto de um sistema eleitoral "centrado no candidato" (SAMUELS, 1997), de um modelo de comunicação política em que o papel dos partidos tem alguma relevância nas campanhas eleitorais, afastando assim a disputa proporcional do total "jogo livre" individualista e sem partido defendido por Mainwaring (1991).

A pretensão aqui está longe da absolutização, como ferramenta eficaz eleitoralmente, da campanha televisiva nas eleições proporcionais. Na mesma linha de Albuquerque et al. (2008), o que se pretende é avaliar "as consequências concretas" do modelo de propaganda eleitoral brasileiro do ponto de vista "das campanhas eleitorais e dos partidos políticos" (ALBUQUERQUE et al., 2008, P.465).

O “corpus" da presente pesquisa compreende 39 (trinta e nove) programas eleitorais (tarde e noite), para a Câmara dos Deputados (CD), veiculados na televisão aberta de 17 de agosto a 30 de setembro do ano de 2010, no estado do Rio Grande do Sul. No total, analisouse 1845 "peças" ou "segmentos" do HGPE dos 11 (onze) partidos com representação na bancada gaúcha do legislativo federal durante a legislatura de 2007 a 2011, a saber: PSOL, PT, PCdoB, PDT, PSB, PMDB, PPS, PSDB, PTB, DEM, PP. Dos 214 candidatos considerados "aptos" a disputar uma vaga na CD por esses partidos naquela eleição, 175 obtiveram alguma exposição no HGPE a deputado federal. Ou seja, 39 ficaram fora da campanha eletrônica pela TV. Ao final da pesquisa, contabilizou-se mais de 9 (nove) horas de material coletado e analisado.

\section{O CONTEXTO ELEITORAL DE 2010 E A EXPOSIÇÃO DOS CANDIDATOS NO HGPE PARA DEPUTADO FEDERAL}

Nas eleições estaduais de 2010, nove candidatos se lançaram à disputa do governo do estado do Rio Grande do Sul. Dentre os candidatos, estava a então detentora do cargo e candidata à reeleição, Yeda Crusius (PSDB), que contava com o apoio de mais sete legendas 
(PP, PSL , PSC , PPS , PHS , PRB , PTdoB); Tarso Genro (PT, PSB, PR e PCdoB), ex-chefe do executivo municipal porto-alegrense e ex-ministro do governo Lula; e José Fogaça (PMDB, PDT, PTN, PSDC), ex-senador e também ex-prefeito de Porto Alegre.

Para além desses três candidatos, figuraram candidaturas menores: Pedro Ruas (PSOL), Vereador de Porto Alegre, membro fundador e ex-presidente Regional do PDT; Montserrat Martins (PV), médico psiquiatra, estreante em disputas eleitorais; e Aroldo Medina (PRP), oficial da Brigada Militar. Por fim, coadjuvaram os representantes de siglas de pequena expressão: o PSTU apresentou Julio Flores; o PMN, o empresário Carlos Schneider; e o PCB, o advogado Humberto Carvalho.

Os percentuais alcançados por Fogaça e Yeda não impediram a vitória do candidato do PT ainda no primeiro turno, feito inédito no Estado desde 1990, quando passou a vigorar o sistema de dois turnos na eleição para o executivo estadual.

Tabela 1 - Resultado da eleição para Governador do Rio Grande do Sul, 2010

\begin{tabular}{llc}
\hline Candidato & Partido/Coligação & Votação \\
\hline Tarso Genro & PT/PSB/PCdoB/PR & 3.416 .460 \\
José Fogaça & PMDB/PDT/PSDC/PTN & 1.554 .836 \\
Yeda Crusius & PSDB / PP / PSL / PSC / PPS / PHS / PRB / PTdoB & 1.156 .386 \\
Montserrat Martins & PV & 93.466 \\
Pedro Ruas & PSOL & 37.934 \\
Aroldo Medina & PRP/PTC & 11.264 \\
Julio Flores & PSTU & 7.938 \\
Carlos Schneider & PMN & 5.475 \\
Humberto Carvalho & PCB & 1.889 \\
Total & & $\mathbf{6 . 2 8 5 . 6 4 8}$ \\
\hline
\end{tabular}

Fonte: TRE/RS

No âmbito da eleição à CD, estiveram em disputa 31 cadeiras, que foram postuladas por um total de 272 candidatos considerados “aptos" pela Justiça Eleitoral. No total, 25 partidos apresentaram listas em 2010: DEM, PCdoB, PCB, PDT, PHS, PMDB, PMN, PP, PPS, PR, PRB, PRP, PSB, PSC, PSDB, PSDC, PSL, PSOL, PSTU, PT, PTdoB, PTB, PTC, PTN, PV. Do total, 42 inscritos acabaram excluídos da eleição. Dos excluídos, vinte e dois foram por "indeferimento" (PSOL,8; PCdoB,1; PMN,1; PDT,1; PTC,3; PTB, 2; PV,3; PSDB,1; PRP;2); e vinte por "renúncia" posterior à homologação do pedido de candidatura pelo TRE (PMDB, 6; PDT; 2; PP, 2; PSDB,3; PTB,2; PV,5).

Um elemento decisivo nas proporcionais é a questão do formato do cálculo de distribuição das cadeiras, como adverte Tavares (1999). Afinal, "para obter sua vaga, é 
necessário primeiro que um partido atinja o coeficiente eleitoral" (ALBUQUERQUE et al. 2008, P. 473). Exatamente por isso cabe destacar que jamais o HGPE, por si só, vai eleger alguém. No caso da eleição a deputado federal no RS, em 2010, o caso mais dramático e exemplificativo da importância do cociente eleitoral foi o da deputada federal Luciana Genro: nona mais votada da lista geral, com 129.501 votos, não conseguiu se eleger porque seu partido, o PSOL, não rompeu o cociente eleitoral. Luciana teve a segunda maior exposição no HGPE, com 1105 segundos no total. Na outra ponta, o Dr. Alexandre Roso, do PSB, com 28.236 votos e com um dos menores tempos de exposição no HGPE (196 segundos), elegeu-se para a CD puxado pela votação de Manuela D’ávila (PCdoB) e Beto Albuquerque (PSB): pela ordem, os dois candidatos mais votados da coligação "Unidade Pelo Rio Grande" e daquela eleição. Dentre os candidatos nas faixas de maior destaque, um caso que se destaca ainda é o de Assis Melo (PCdoB), que com um total de 818 segundos (quinta maior exposição), angariou aproximadamente 47 mil votos e também eleito graças ao desempenho dos puxadores de voto de sua coligação.

Em geral, no entanto, as condições de exposição no HGPE para deputado federal em análise não foram as mais favoráveis. Com o grande número de candidatos, o tempo de TV da maioria dos postulantes à vaga no legislativo foi bastante inferior ao da psolista nãoeleita Luciana Genro ou dos comunistas eleitos Assis Melo e Manuela D'ávila. Dos candidatos com presença na televisão, apenas 4 (quatro) tiveram, em média, exposição acima de 20 segundos (Grande Exposição), ao longo da campanha; 13 (treze) tiveram entre 10 e 20 segundos (Média Exposição); 80 (oitenta) candidatos ocuparam a faixa de 5 a 10 segundos de exposição (Pequena Exposição); e, por fim, 78 (setenta e oito) postulantes ocuparam a menor faixa de exposição (Nenhuma Exposição): menos de 5 segundos.

Gráfico 1 - Exposição no HGPE (média de tempo)

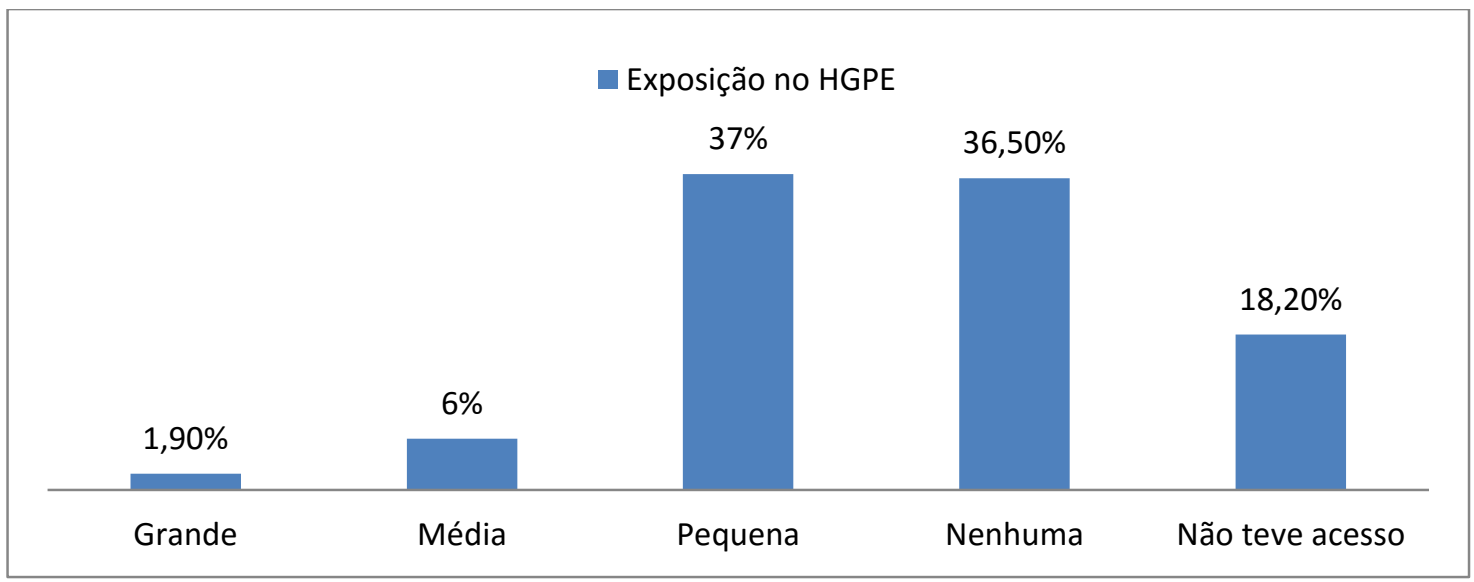


Fonte: Núcleo de Estudos Sobre Poder, Partidos e Eleições (NEPPE) do Centro Brasileiro de Pesquisas em Democracia (CBPD) - PUCRS N: 175

Como visto, há um número expressivo de candidatos nas faixas mais baixas de tempo médio de exposição. E sobre a eficácia do tempo de TV na proporcional, ela não é evidente principalmente quando se avalia a distribuição do mesmo entre os eleitos. De todos, apenas 2 (dois) candidatos romperam a barreira da média de 20 segundos ao longo da propaganda eleitoral, tendo, assim, grande exposição: Manuela D’ávila (PCdoB), candidata mais votada, e Beto Albuquerque (PSB), segundo mais votado. Sete dos eleitos apresentaram uma exposição média, situando-se na faixa de 10 a 20 segundos. E a grande maioria teve exposição pequena: 17 (dezessete) eleitos ficaram com média entre 5 a 10 segundos. Por fim, 4 (quatro) se situaram na faixa de nenhuma exposição (menos de 5 segundos), quais sejam: Renato Molling (PP), Enio Bacci (PDT), Vieira da Cunha (PDT) e Alexandre Roso (PSB). Mas não interessa, neste trabalho, discutir em seus pormenores a eficácia eleitoral da propaganda eleitoral proporcional, alvo de tantas controvérsias e debate na literatura especializada. Não é esse o objetivo. Trata-se de investigar como os partidos utilizam o tempo de televisão internamente como um "incentivo seletivo" aos candidatos. Para isso, no plano metodológico, utilizou-se um número maior de faixas ${ }^{10}$ na análise da distribuição intrapartidária do tempo de exposição televisiva, não se adotando apenas 4 (quatro) faixas (Gráfico 1), como encontrado no trabalho de Albuquerque et al. (2008). Além disso, a quantificação das exposições individuais dos candidatos não foi feita com base na média de tempo de cada candidato por programa (Gráfico 1), mas conforme o total geral de exposição (em segundos) durante toda a veiculação do HGPE a deputado federal em 2010.

10 Faixas de Exposição no HGPE (Total de Segundos): Baixíssima: 6 - 100 segundos; Baixa: 100 - 200; Média/Baixa: 200 - 300; Média: 300 - 400; Média/Alta: 400 - 500; Alta: 500 - 1000; Altíssima: Acima de mil segundos. 
Gráfico 2 - Distribuição Intrapartidária dos Candidatos por Faixas de Exposição no HGPE (tempo total)

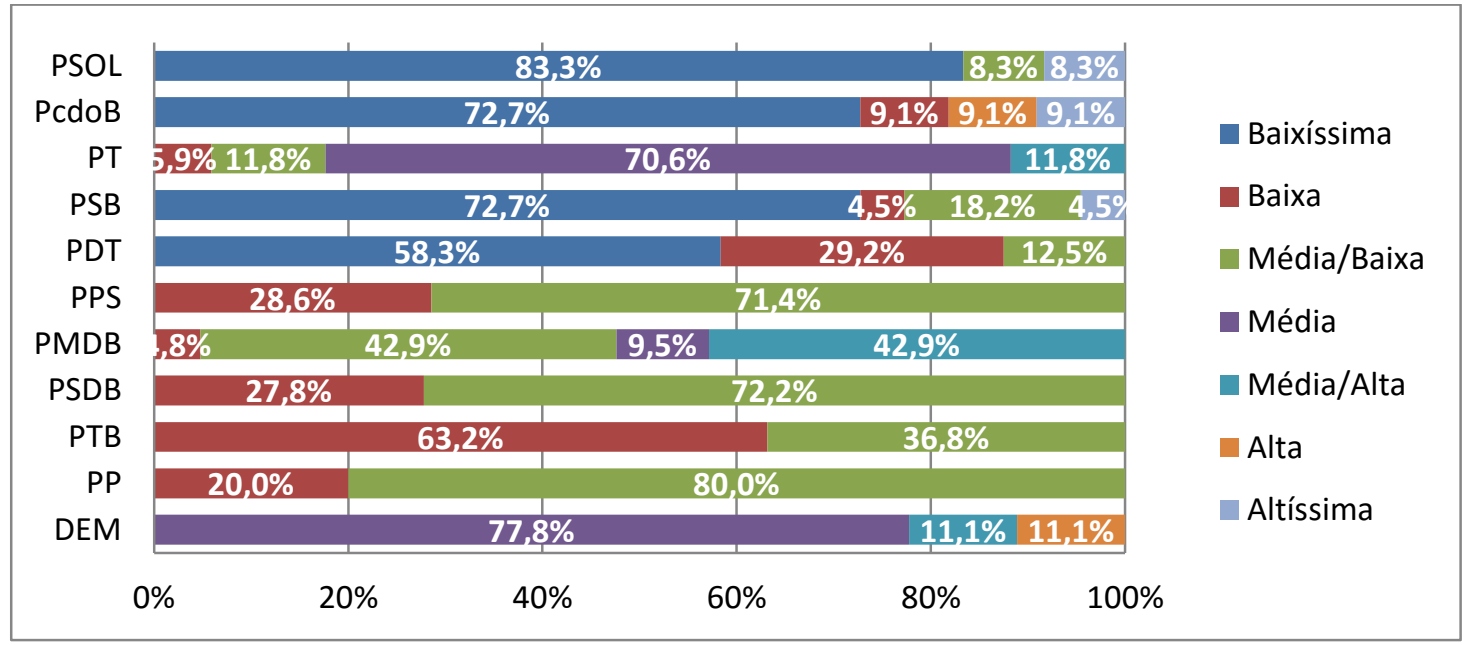

Fonte: Núcleo de Estudos Sobre Poder, Partidos e Eleições (NEPPE) do Centro Brasileiro de Pesquisas em Democracia (CBPD) - PUCRS N:175

Três partidos pequenos no Rio Grande do Sul, em estrutura e com tempo menor de TV, optaram, claramente, pelo fortalecimento de seus "puxadores de voto", com exposição "Altíssima”: PSB (Beto Albuquerque), PCdoB (Manuela D’ávila) e PSOL (Luciana Genro). Ainda no PCdoB, Assis Melo, já citado, ocupou sozinho a faixa de "Alta" exposição.

Dispondo de mais tempo e de um maior número de candidatos competitivos, PT, PMDB e PP recorreram, respectivamente, conforme o gráfico acima, a estratégias de exposição "média", "média/alta" e "média/baixa". Em partidos grandes, com listas mais competitivas, a estratégia do "puxador de voto" tem, em tese, maior constrangimento, pois a margem de manobra dos dirigentes para privilegiar algum candidato é mínima. No entanto, entre outros partidos pesquisados, como PPS e PSDB (ainda pequenos no Estado), houve também maior concentração de candidatos nas faixas de "média" e "média/baixa" exposição. No DEM, Onyx Lorenzoni (DEM), por seu potencial de votos, obteve maior destaque, ocupando sozinho a faixa de "Alta" exposição. Com menos tempo televisivo, os trabalhistas PDT e PTB, que possuem estrutura destacada no Rio Grande do Sul, optaram também pela exposição "média/baixa", "baixa" e "baixíssima" de seus candidatos, sendo que o PTB reservou um razoável tempo para a promoção de sua simbologia partidária e legenda. Se nota, em geral, que um padrão mais igualitário de distribuição do espaço televisivo, em faixas "médias" de exposição, sem concentração de tempo em poucos candidatos, foi a tônica na maioria das siglas pesquisadas. 
O argumento encontrado no estudo de Carneiro (2009) dá conta das estratégias de exposição no HGPE adotada por PSOL, PSB e PCdoB: a partir da projeção do desempenho individual de Luciana Genro, Beto Albuquerque e Manuela D’ávila nas urnas, tais partidos concentraram mais seu tempo televisivo, privilegiando esses três concorrentes como “puxadores de voto”. A votação na eleição anterior - hipótese proposta por Nicolau (2006) - e a evidente popularidade dos três candidatos foram, para isso, decisivas. De resto, nos outros partidos (com a exceção do DEM), houve uma maior pulverização do tempo entre os concorrentes. Isto é, "os partidos de fato distribuem desigualmente o tempo entre seus candidatos, embora se valham de estratégias muito diferentes para tal" (Albuquerque et al. 2008). E, nesta pesquisa, em muitos deles, a distinção não foi tão efetiva, pois a maioria dos candidatos se situou em faixas de "média" exposição, sem grande concentração de tempo.

No entanto, mesmo em se constatando que a distribuição mais igualitária do tempo televisivo foi dominante entre as siglas pesquisadas, propõe-se, nesta parte final do texto, avaliar o peso de uma variável propriamente interna aos partidos na formatação do HGPE nas proporcionais: o tempo de filiação dos candidatos. O tempo de filiação "permite estimar a consistência dos laços de lealdade intra-partidários" (SANTOS, 2000, P. 178-179), ou seja, o grau de vinculação de cada indivíduo com sua respectiva organização política. Assim, cabe perguntar se candidatos com mais tempo de partido podem receber um maior montante do “incentivo seletivo" (PANEBIANCO, 2005) tempo de televisão, monopolizado pelos partidos políticos no Brasil.

A aplicação do coeficiente de Pearson ao conjunto de candidatos com exposição televisiva na eleição de 2010 , por 10 dos 11 partidos pesquisados ${ }^{11}$, teve como resultado uma correlação bastante modesta, da ordem de 0,36 ( $\mathrm{n}=175)$. Aplicando o coeficiente para mensurar a correlação entre tempo de filiação e quantidade de tempo no HGPE por partido, foram obtidos resultados um pouco mais expressivos, no entanto. No PSB, o coeficiente resultante foi o mais expressivo: 0,68 $(\mathrm{n}=26)$; No PDT, o coeficiente resultante foi de 0,55 ( $\mathrm{n}=26)$; no PP, de 0,50 ( $\mathrm{n}=18)$; no DEM, de 0,49 ( $\mathrm{n}=12)$; e no PTB, de 0,40 ( $\mathrm{n}=19)$.

\footnotetext{
11 Optou-se pela exclusão do PSOL da análise em virtude de o partido ter sido fundado muito recentemente em relação à eleição de 2010: somente no ano de 2005.
} 
Gráfico 3 - Coeficiente de Pearson (Tempo de Filiação e Tempo de Exposição no HGPE)

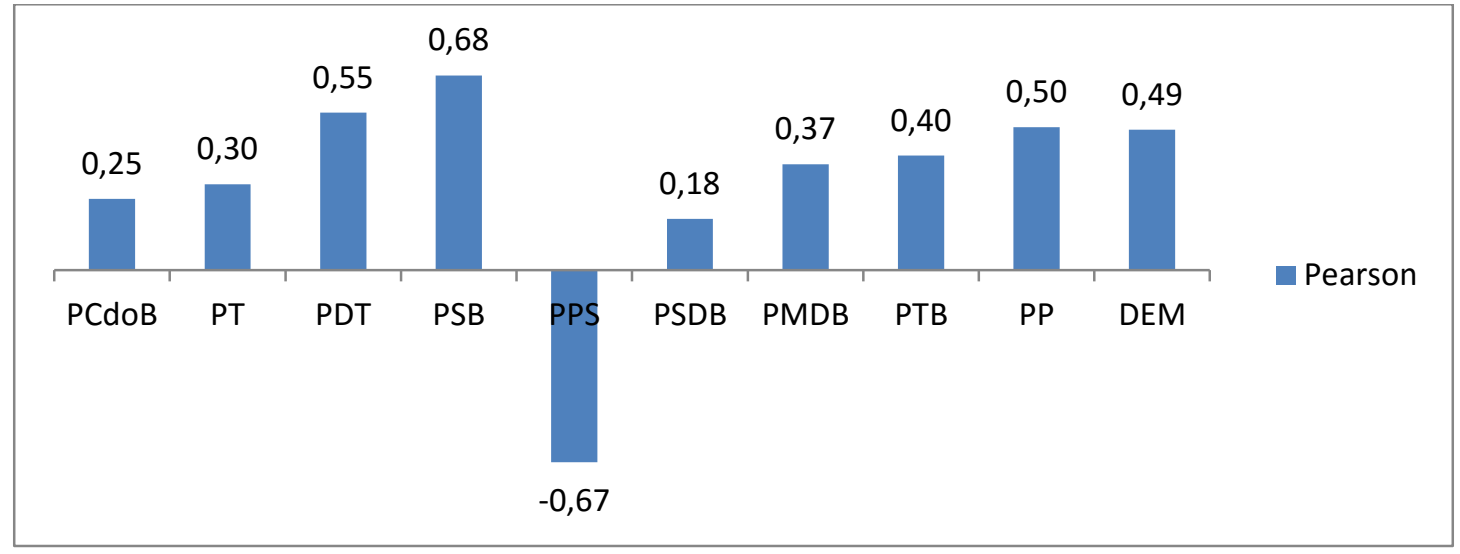

Fonte: Núcleo de Estudos Sobre Poder, Partidos e Eleições (NEPPE) do Centro Brasileiro de Pesquisas em Democracia (CBPD) - PUCRS N:175

A correlação relevante encontrada entre os candidatos do PSB, que adotou uma estratégia fortemente estratificada de distribuição de seu tempo televisivo, parece, a princípio, demonstrar que, neste partido, o grau de vinculação partidária teria tido peso na definição do formato do HGPE. Cabe ressaltar, porém, que Beto Albuquerque, o puxador de votos dos socialistas, detinha também o maior tempo de filiação entre seus colegas de lista: 24 anos. Sem Beto, a correlação no PSB seria bem mais modesta, da ordem de 0,38. Nesse caso, o candidato de maior destaque possuía, ao mesmo tempo, a melhor projeção de desempenho nas urnas e a maior longevidade partidária. O mesmo não foi encontrado no PCdoB, com correlação de 0,25: Manuela D’ávila detinha a melhor projeção de desempenho, mas apenas o quinto maior tempo de filiação: 10 anos. No caso de PDT e PP, com correlações razoáveis, ambos recorreram a uma distribuição mais homogênea do tempo, sem privilegiar decisivamente algum candidato, o que prejudica a hipótese aqui apresentada.

Em resumo, o que se pode dizer é que a distribuição homogênea do tempo de televisão na grande maioria dos partidos pesquisados prejudicou a aplicação da hipótese aqui proposta. Para um teste efetivo, uma maior segmentação do tempo no interior dos partidos é necessária. E nos poucos partidos com distribuição mais estratificada neste estudo especificamente, PSB e PCdoB - a projeção de desempenho dos "puxadores de voto" parece ter sido, de fato, determinante para seu maior destaque. Por fim, mesmo com segmentação de tempo um pouco maior, por possuírem mais candidatos na faixa de "média/alta exposição", PT e PMDB apresentaram correlações modestas entre tempo de filiação partidária e tempo de exposição no HGPE. 


\section{A IMAGEM PARTIDÁRIA NO HGPE PARA DEPUTADO FEDERAL EM 2010}

A segunda tarefa deste trabalho é a avaliação comparativa do grau de investimento dos partidos em sua imagem pública a partir da análise das estratégias eleitorais presentes na propaganda eleitoral à $\mathrm{CD}$. Para isso, recorreu-se, em consonância com o trabalho de Dias (2009), a categorias que pudessem dar conta da maior amplitude possível de estratégias, quais sejam: A) Referências Partidárias Diretas: a "legenda", o "símbolo" e "bandeiras" que possam identificar o partido. B) Outras Referências Coletivistas: simbologia própria da coligação. C) Referências à Candidatura Majoritária: promoção da imagem do candidato ao executivo. Por fim, optou-se por reorganizar o referencial analítico de Dias (2009). Com a categoria Protagonistas, pretendeu-se isolar as estratégias eleitorais que qualitativamente são as mais impregnadas de partidarismo, tais como: Menção explícita ao partido, Menção à liderança partidária, Aparição de dirigente partidário, Pedido Explícito de voto na Legenda do partido. Das 1845 "peças" ou “segmentos” do HGPE analisados, detectou-se um total de 6496 estratégias eleitorais por meio das categorias adotadas.

Gráfico 4 - Estratégias Eleitorais utilizadas no HGPE (Deputado Federal/ RS - 2010)

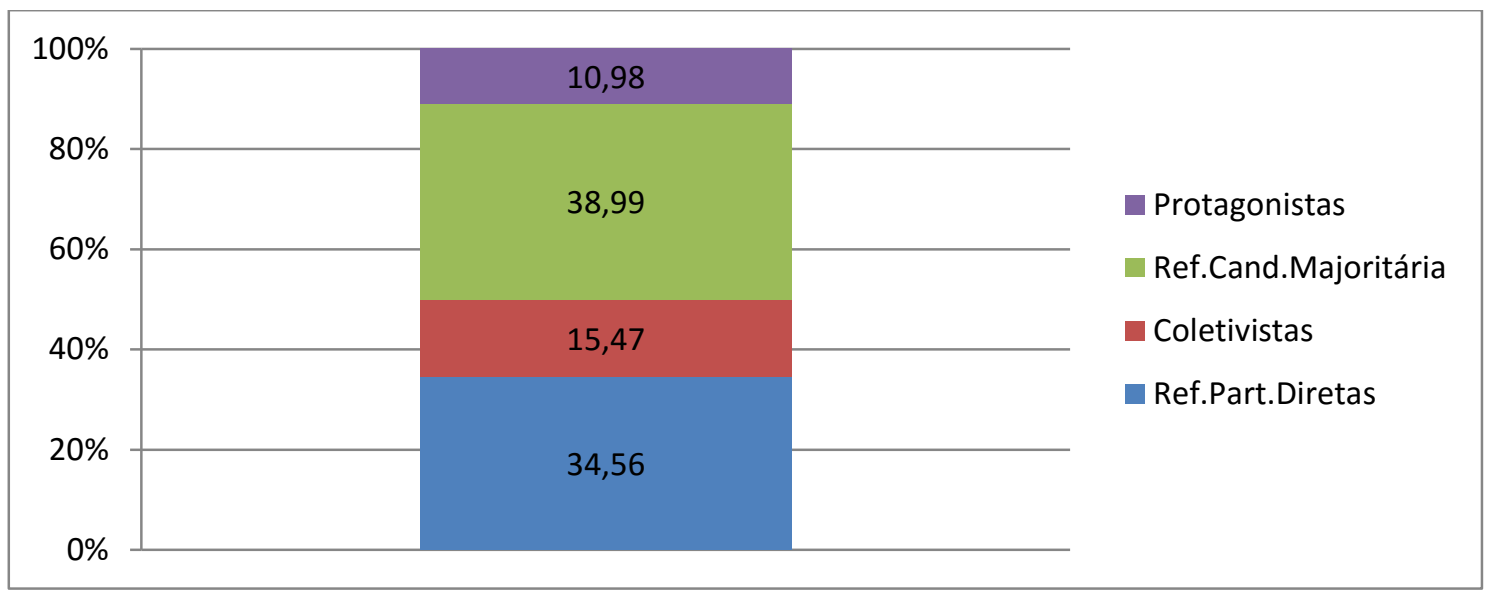

Fonte: Núcleo de Estudos Sobre Poder, Partidos e Eleições (NEPPE) do Centro Brasileiro de Pesquisas em Democracia (CBPD) - PUCRS N: 6496

As estratégias de mais alto partidarismo - protagonistas - atingiram sozinhas $11 \%$ do total de estratégias eleitorais presentes no HGPE para Deputado Federal no Rio Grande do Sul, em 2010. Somando as referências partidárias diretas com as protagonistas temse um total de $45 \%$ das estratégias detectadas. Além disso, mesmo que a grande maioria dos partidos tenha concorrido em coligações ${ }^{12}$, o percentual de outras referências coletivistas (apoio à coligação) é o menor: 15\%. Com grande destaque, por fim, aparecem as referências à candidatura majoritária, com 39\%. Em um "sistema centrado no candidato" (Samuels,

\footnotetext{
12 Do total de 11 (onze) partidos analisados, apenas PT e PSOL não concorreram em coligações.
} 
1997), com coligações proporcionais permitidas legalmente e alto número de concorrentes, chama atenção que quase metade das estratégias eleitorais presentes numa campanha televisiva a deputado federal seja composta por "signos" estritamente partidários. Parte deles, ainda que menos abundante, altamente "impregnada" de partidarismo.

Passando para a comparação interpartidária, cabe avaliar a natureza das estratégias eleitorais presentes na propaganda. Os tipos de estratégia têm certa diferença qualitativa: referências provenientes do suporte à campanha majoritária "contam com signos estritamente individualistas, baseados na imagem do candidato a prefeito (governador ou presidente, conforme o caso)" (DIAS, 2009, P.13). As referências de apoio à coligação, por se basearem em signos "coletivistas", também não contribuem diretamente para a fixação da imagem de cada partido junto ao eleitorado. O "partidarismo" eleitoral pode ser, assim, melhor vislumbrado na contribuição de cada partido para o total geral de referências partidárias diretas e protagonistas presentes no HGPE para Deputado Federal.

Tabela 2- Estratégias Eleitorais utilizadas no HGPE (por Partido)

(Deputado Federal/ RS - 2010)

\begin{tabular}{|c|c|c|c|}
\hline $\begin{array}{l}\text { Partid } \\
\text { o }\end{array}$ & $\begin{array}{c}\text { Referências Partidárias Diretas e } \\
\text { Protagonistas }\end{array}$ & $\begin{array}{c}\text { Referências à } \\
\text { Majoritária }\end{array}$ & $\begin{array}{c}\text { Apoio à } \\
\text { Coligação }\end{array}$ \\
\hline PSOL & $12 \%$ & $6 \%$ & $0 \%$ \\
\hline PT & $18 \%$ & $13 \%$ & $0 \%$ \\
\hline PCdoB & $10 \%$ & $20 \%$ & $0 \%$ \\
\hline PSB & $8 \%$ & $21 \%$ & $4 \%$ \\
\hline PDT & $9 \%$ & $10 \%$ & $8 \%$ \\
\hline PPS & $2 \%$ & $7 \%$ & $16 \%$ \\
\hline PMDB & $7 \%$ & $8 \%$ & $9 \%$ \\
\hline PSDB & $7 \%$ & $9 \%$ & $17 \%$ \\
\hline РTB & $14 \%$ & $0 \%$ & $16 \%$ \\
\hline PP & $5 \%$ & $8 \%$ & $16 \%$ \\
\hline DEM & $8 \%$ & $0 \%$ & $16 \%$ \\
\hline Total & $100 \%$ & $100 \%$ & $100 \%$ \\
\hline $\mathbf{N}:$ & 2960 & 2533 & 1003 \\
\hline
\end{tabular}

Fonte: Núcleo de Estudos Sobre Poder, Partidos e Eleições (NEPPE) do Centro Brasileiro de Pesquisas em Democracia (CBPD) - PUCRS

Observa-se que 18\% do total de referências partidárias diretas e protagonistas presentes no HGPE em análise pertencem ao Partido dos Trabalhadores. Ao seu lado, se encontra o PTB, com 14\%. Em seguida, o PSOL, com 12\%, o PCdoB, com $10 \%$ e o PDT, $\operatorname{com} 9 \%$. O PSB ocupa o sexto lugar no ranqueamento, com $8 \%$, empatado com o DEM. O PMDB está em sétimo lugar, com 7\%, empatado com o PSDB. Dentre os partidos com os menores percentuais, encontram-se o PP, com 5\%, e o PPS, com apenas $2 \%$. 
O PT, nesta pesquisa, confirmou o que vem sendo dito pela literatura (DIAS, 2009, 2011, 2013; SAMUELS, 1997) quanto a sua capacidade de constituição de reputação eleitoral partidária. Em seu estudo longitudinal sobre a construção da imagem partidária no país, Dias (2011) destaca o investimento que esse partido tem feito no sentido de constituir uma marca pública, para além das questões conjunturais de cada eleição e da própria profissionalização das campanhas eleitorais. Mas, partindo do caso petista, é possível dizer que a projeção de imagem partidária pública, isto é, o "partidarismo eleitoral" - enquanto um "incentivo coletivo" ou de "identidade", nos termos de Panebianco (2005) - seria mais próprio das organizações de esquerda estudadas? Isto é, o espectro "ideológico" partidário teria peso explicativo neste processo?

Conforme a disposição partidária no eixo esquerda-direita (KINZO, 1993), do conjunto dos cinco partidos com maior contribuição ao total de referências partidárias diretas e protagonistas, quatro estão, por definição, à esquerda do espectro ideológico, pela ordem: PT, PSOL, PCdoB e PDT. Os mesmos, na gramática do HGPE, se valeram de tipos mais explícitos de estratégia para evidenciar sua imagem pública (referências protagonistas): o PT do apelo ao voto de legenda ("vote nos candidatos do PT para deputado federal!") e da menção às lideranças partidárias de maior destaque (basicamente, menções ao ex-presidente Lula). O PSOL se caracterizou, de forma destacada, pelo uso das menções diretas ao partido, por meio da vinculação entre número e legenda (“50 é PSOL!”), ao abrir seu programa. O PDT fixou-se, mais amplamente, no pedido de voto na "bancada 12". Em alguns programas, foi feita menção às lideranças partidárias e utilizadas imagens dos trabalhistas históricos (Leonel Brizola, João Goulart e Getúlio Vargas). No dia 24 de agosto, data do suicídio de Vargas, o partido dedicou o programa da proporcional ao grande líder trabalhista e a seus herdeiros. O PCdoB, basicamente, se valeu da menção direta ao partido ("esse é o PCdoB, sempre do teu lado!’'), logo na abertura do seu programa, e do pedido de voto na legenda.

No entanto, para além do posicionamento dos partidos ao longo do eixo esquerda/direita, questões basicamente conjunturais - como, por exemplo, a relação entre a campanha proporcional e a majoritária - e de fundo institucional - como o papel das coligações e o tamanho dos partidos - contribuem para a utilização de estratégias eleitorais mais, ou menos, partidaristas na campanha proporcional. Em primeiro lugar, muitas estratégias correspondem ao interesse das siglas no curto prazo da eleição e não possuem caráter estritamente ideológico, mas pragmático. Tais estratégias não buscam, assim, promover, de forma sincera, a imagem pública do partido, mas visam, por outras vias, a seu fortalecimento. Estratégias de suporte à candidatura majoritária (com um total de 38\%, neste 
estudo), por exemplo, apesar de seu caráter mais personalista, buscam o fortalecimento eleitoral partidário por meio da tentativa de compartilhamento da popularidade da candidatura majoritária com os candidatos ao legislativo. Além disso, cabe ainda lembrar que o apoio explícito ao candidato da majoritária no HGPE proporcional também expressa influência do comando partidário sobre o uso do tempo naquele espaço.

Entre todos os partidos pesquisados, PSB e PCdoB foram os que mais investiram em referências à candidatura majoritária em seus programas a deputado federal. Na eleição de 2010, ambos participaram da coligação majoritária liderada por Tarso Genro, do PT, ao executivo estadual gaúcho. O PCdoB indicou Abgail Pereira, liderança do partido na cidade de Caxias do Sul, para a disputa ao Senado junto com Paulo Paim, do PT. O PSB indicou o candidato a vice-governador na chapa de Genro ao Piratini, o ex-deputado estadual Beto Grill. Na proporcional para a CD, ambos concorreram coligados sem o PT. Ao final do primeiro turno, como a campanha de Genro praticamente "deslanchou" rumo à vitória, a presença do candidato petista na propaganda de PSB e PCdoB na proporcional, pedindo diretamente voto nos candidatos comunistas e socialistas, foi potencializada.

Nesse emparceiramento entre a campanha majoritária e a proporcional, PSB e PCdoB também apresentaram outra estratégia clara: dar máxima exposição individual aos seus dois “puxadores de voto”, Manuela D’ávila e Beto Albuquerque. Com a priorização dos dois candidatos, o apelo de Genro ao voto nos candidatos do PSB e PCdoB acabava, devido ao formato HGPE desses partidos, se revertendo para uma valorização ainda maior do tempo de exposição de Manuela e Beto Albuquerque naquele espaço. A estratégia mais personalista do suporte à majoritária foi, assim, combinada com uma estratégia eleitoral individualista: destaque máximo ao "puxador de voto".

Ainda sobre referências partidárias diretas e protagonistas, a forte presença de marcas partidárias na propaganda do PTB, partido considerado de direita pela classificação tradicional, e que obteve o segundo maior percentual de do HGPE com 14\%, pode ser explicada pelo fato conjuntural desse partido, em coligação com o DEM, não ter apresentado, ou apoiado, candidatura ao executivo estadual em 2010, o que "abriu espaço" para uma maior ênfase à simbologia partidária na propaganda eleitoral dessas siglas.

Quanto à coligação na proporcional, essa prática influencia para que estratégias partidaristas tenham maior incidência entre partidos não coligados, até pela própria racionalidade eleitoral inerente à disputa. Como a coligação faz com que os votos de legenda, de qualquer partido integrante, sejam revertidos para o conjunto da aliança, “independentemente de um partido ser de esquerda ou de direita, se estiver coligado a outros, 
seus candidatos terão bons motivos para desviar os votos da legenda para suas próprias candidaturas” (Samuels, 1997, p. 503). Por essa lógica, o apelo partidário direto, em caso de coligação, não interessa tanto.

O fato de não terem feito coligação com outros partidos nas proporcionais abriu maior espaço para o uso de referências partidárias diretas e protagonistas na campanha do PT e do PSOL. No caso do PSOL, outro fator foi importante para isso: o tamanho da sigla. Por ser um partido pequeno e, por isso, detentor de uma fatia modesta do fundo partidário, "uma estratégia eleitoral barata de curto prazo é promover a sigla, atraindo eleitores que não estão ligados a redes de patronagem ou que estejam interessados em partidos de orientação programática" (SAMUELS, 1997, P. 503). O PPS, no entanto, atuou em lógica contrária à do PSOL: partido pequeno que é, mas coligado com sete partidos, optou por dar amplo apoio à coligação. PSDB, PP, assim como DEM e PTB (estes aliançados, mas sem candidatura à majoritária, como dito) também se destacaram no uso de estratégias de apoio à coligação.

Em termos gerais, no entanto, verificou-se que a prática das coligações, em dissonância com o postulado de Samuels (1997), não inibiu de forma decisiva o partidarismo na campanha televisiva analisada. Se, por um lado, os dois partidos que não concorreram em alianças - PSOL e PT - obtiveram, respectivamente, o primeiro e o terceiro maior percentual de referências partidárias diretas e protagonistas, deve-se considerar também que, em um universo de 11 (onze) siglas em que 9 (nove) delas concorreram coligadas, houve espaço razoável para essas "marcas" propriamente partidaristas, que chegaram a 45\% do total das estratégias eleitorais, tendo o PTB, coligado ao DEM, atingido o segundo maior percentual nesse quesito.

Por fim, nesse ponto, cabe ainda lembrar que, conforme a Lei $n^{\circ} 9.504 / 97$, art. $6^{\circ}$, $\S 2^{\circ}$ - "Na propaganda para eleição majoritária, a coligação usará, obrigatoriamente, sob sua denominação, as legendas de todos os partidos que a integram; na propaganda para eleição proporcional, cada partido usará apenas sua legenda sob o nome da coligação". Existe, assim, a obrigatoriedade legal de mesmo as siglas coligadas utilizarem, cada uma, apenas a própria legenda no HGPE proporcional, reforçando a presença de referências partidárias diretas e protagonistas naquele espaço (contrariamente ao que é imposto, em caso de coligação, à propaganda eleitoral da majoritária). No entanto, isso não impede, como visto até aqui, que existam disparidades relevantes entre os partidos quanto aos tipos de estratégias eleitorais empregadas na propaganda eleitoral das proporcionais. 


\section{CONSIDERAÇÕES FINAIS}

O presente estudo procurou avaliar empiricamente o papel e a relevância dos partidos políticos na formatação da propaganda eleitoral gratuita proporcional a partir da análise de caso do HGPE para deputado federal veiculado nas eleições de 2010 no estado do Rio Grande do Sul. Confirmou-se, em síntese, o potencial da campanha televisiva para a difusão da simbologia partidária, com certo "protagonismo" do Partido dos Trabalhadores e das agremiações de esquerda nessa prática. Porém, o exemplo do PTB gaúcho atesta que qualquer legenda, de direita ou de esquerda, pode promover efetivamente sua imagem e simbologia, por motivação ideológica, conjuntural ou mesmo pragmática, valendo-se do modelo "partidário" brasileiro de propaganda eleitoral. Tal modelo tem, como dito, se contraposto ao individualismo político nas campanhas eleitorais proporcionais.

Quanto à discussão sobre o tempo de exposição televisiva dos candidatos no HGPE proporcional, verificou-se a distribuição homogênea do tempo nos grandes partidos e uma estratégia clara de estratificação do mesmo em siglas menores, no caso, PSB, PCdoB e PSOL, que optaram pela estratégia do "puxador de voto". Essa distribuição mais homogênea do tempo prejudicou, ao fim, a hipótese aqui apresentada de correlação entre tempo de exposição na TV e longevidade partidária. Caberá, assim, retomá-la em trabalhos futuros.

\section{REFERÊNCIAS}

ALBUQUERQUE, A. 1999. Aqui você vê a verdade na tevê - A propaganda politica na televisão. Niterói: Publicações do Mestrado em Comunicação, Imagem e Informação - UFF.

ALBUQUERQUE, A.; DIAS, M. R. 2002. Propaganda política e a construção da imagem partidária no Brasil. Civitas: Revista de Ciências Sociais, v. 2, n. 2, p. 309-326.

ALBUQUERQUE, A. 2005. Política partidária e política midiática: substituição ou coexistência. Contemporânea, v. 3, n. 1, p.9-37, 2005.

ALBUQUERQUE, A.; STEIBEL, F. B. e CARNEIRO, C. M. Z. 2008. A Outra face do horário gratuito: partidos políticos e eleições proporcionais na televisão. Dados, vol.51, n.2, p. $459-487$.

ALBUQUERQUE, A. 2009. Notas para uma agenda da pesquisa sobre a propaganda política na televisão no Brasil. Eco (UFRJ), v. 12, n.3, p. 4-10.

AMES, B. 2003. Os entraves da democracia no Brasil. Rio de Janeiro: Fundação Getúlio Vargas.

ANDRADE DOS SANTOS, J. C. 2011. Coligações em Eleições Municipais: Porto Alegre (2004 e 2008). Porto Alegre, Dissertação de Mestrado em Ciências Sociais, Faculdade de Filosofia e Ciências Humanas da Pontifícia Universidade Católica do Rio Grande do Sul. 
CARNEIRO, A. R. 2009. Processo de Seleção de Candidatos ao Cargo de Deputado Federal no Estado do Rio de Janeiro - Organizando as "Peças" do "Quebra-Cabeça". Rio de Janeiro, Tese de Doutorado em Ciência Política, Instituto Universitário de Pesquisas do Rio de Janeiro.

CERVI, E. U. 2011. O uso do HGPE como recurso partidário em eleições proporcionais no Brasil: um instrumento de análise de conteúdo. Opinião Pública, Campinas, vol. 17, $\mathrm{n}^{\circ}$ 1, p. 106-136.

DIAS, M. R.2009. Coadjuvantes no próprio espetáculo: os partidos políticos na propaganda eleitoral brasileira. $33^{\circ}$ Encontro Anual da ANPOCS, Caxambu.

DIAS, M. R.2011. Nas Brumas do HGPE: a Imagem Partidária nas Campanhas Presidenciais Brasileiras (1989 a 2010). $35^{\circ}$ Encontro Anual da ANPOCS, Caxambu.

DIAS, M. R.; MENEZES, D. B.; FERREIRA, G. C. 2012. “A quem serve o Graal?”: um estudo sobre a classificação ideológica dos partidos políticos através de seus projetos de lei na Alergs (2003 a 2006). Civitas: Revista de Ciências Sociais, v. 12, n², p. 209-235, 2012.

DIAS, M. R. 2013. Nas Brumas do HGPE: a Imagem Partidária nas Campanhas Presidenciais Brasileiras (1989 a 2010). Opinião Pública, Campinas, v. 19, n 1, p. 198-219.

FERREIRA, G. C. 2012. Recrutamento à Representação Político-Partidária: o caso das eleições de 2010 no Rio Grande do Sul. Porto Alegre, Dissertação de Mestrado em Ciências Sociais, Faculdade de Filosofia e Ciências Humanas da Pontifícia Universidade Católica do Rio Grande do Sul.

KINZO, M. D. 1993. Radiografia do Quadro Partidário Brasileiro. São Paulo: Fundação KonradAdenauer.

KLEIN, C. 2007. O desafio da reforma política: conseqüências dos sistemas eleitorais de listas aberta e fechada. Rio de Janeiro: Mauad X.

MAINWARING, S. 1991. Políticos, partidos e sistemas eleitorais: o Brasil numa perspectiva comparada. Novos Estudos, São Paulo, n. 29, p. 34-58.

MIGUEL, L. F. 2010. Apelos discursivos em campanhas proporcionais na televisão. Política \& Sociedade, v.9, n. 16, p. 151-175.

NICOLAU, J. 2006. O sistema eleitoral de lista aberta no Brasil. Dados, Rio de Janeiro, v. 49, n. 4 , p. $689-720$.

PANEBIANCO, A. 2005. Modelos de Partido: a organização e poder nos partidos políticos. São Paulo: Martins Fontes.

POPKIN, S. L. 1994. The Reasoning Voter: Communication and Persuasion in Presidential Campaigns. Chicago: The University of Chicago Press.

SAMUELS, D. 1997. Determinantes do Voto Partidário em Sistemas Eleitorais Centrados no Candidato: Evidências sobre o Brasil. Dados, Rio de Janeiro, v. 40, n. 3, p.493 - 533.

SANTOS, A. M. 2000. Não se Fazem mais Oligarquias como Antigamente. Recrutamento Parlamentar, Experiência Política e Vinculos Partidários entre Deputados Brasileiros (1946-1998). Porto Alegre, Tese de Doutorado em Ciência Política, Instituto de Filosofia e Ciências Humanas da Universidade Federal do Rio Grande do Sul. 
SCHMITT R.; CARNEIRO, L.P. \& KUSHNIR, K. 1999. Estratégias de campanha no Horário Gratuito de Propaganda Eleitoral em eleições proporcionais. Dados, Rio de Janeiro vol. 42, n², p. 277-301.

TAVARES, J. A. G.1999. O problema do cociente partidário na teoria e na prática brasileiras do mandato representativo. Dados, Rio de Janeiro, v. 42, n. 1. 